\title{
Validation of an FFQ and options for data processing using the doubly labelled water method in children
}

\author{
Alice E Dutman ${ }^{1, *}$, Annette Stafleu ${ }^{1}$, Astrid Kruizinga ${ }^{1}$, Henny AM Brants ${ }^{1}{ }^{\prime}$, \\ Klaas R Westerterp ${ }^{2}$, Cor Kistemaker', Wim JA Meuling ${ }^{1}$ and R Alexandra Goldbohm ${ }^{3}$ \\ ${ }^{1}$ TNO Quality of Life, Postbus 360, 3700 AJ Zeist, The Netherlands: ${ }^{2}$ Department of Human Biology, Maastricht \\ University, Maastricht, The Netherlands: ${ }^{3}$ TNO Quality of Life, Leiden, The Netherlands
}

Submitted 2 February 2010: Accepted 2 June 2010: First published online 16 August 2010

\begin{abstract}
Objective: To validate an FFQ designed to estimate energy intake in children against doubly labelled water (DLW). To investigate how quality control and standard beverage portion sizes affect the validity of the FFQ.

Design: Thirty healthy children, aged 4-6 years, participated. Total energy expenditure (EE) was measured by the DLW method during an observation period of $15 \mathrm{~d}$. At the end of this period parents filled out an FFQ designed to assess the child's habitual energy intake (EI) of the preceding four weeks.

Setting: Validation study in The Netherlands.

Subjects: Thirty healthy children (fifteen boys and fifteen girls), aged 4-6 years. Results: Mean EI (6117 (sD 1025) kJ/d) did not differ significantly from mean EE (6286 (sD 971) kJ/d; $P=0 \cdot 15$ ); the mean EI:EE ratio was $0 \cdot 98$. The Pearson correlation coefficient between EI and EE was $0 \cdot 62$. The Bland-Altman plot showed no systematic bias and a constant bias close to zero. Less intensive quality control of the FFQ maintained the mean EI:EE ratio and decreased the correlation slightly. Using standard instead of individually measured beverage portion sizes decreased the mean EI:EE ratio, but maintained the correlation.

Conclusions: It can be concluded that the developed FFQ is a valid instrument to estimate mean energy intake in a group of 4- to 6-year-old children and performs reasonably well to rank the subjects with respect to energy intake. It is therefore a useful instrument to estimate energy intake in children in surveys and epidemiological studies in The Netherlands.
\end{abstract}

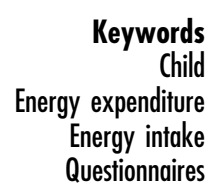

For the assessment of energy intake in large epidemiological studies a valid instrument for use in children is critical. Until children have reached the developmental stage when they are aware of their food intake and can begin to conceptualize time (at approximately 7-8 years of age), reporting of food intake depends on the parents ${ }^{(1)}$. Due to its cost-effectiveness and the possibility for selfadministration by the parent, the FFQ may be a useful instrument for use in large-scale studies. As a suitable FFQ for the assessment of energy intake in Dutch children was not available, we developed an $\mathrm{FFQ}^{(2)}$ based on intake data of children included in the third Dutch National Food Consumption Survey (DNFCS) ${ }^{(3)}$. The doubly labelled water (DLW) method is considered to be the 'gold standard' for the determination of total energy expenditure in free-living subjects ${ }^{(4)}$ and has been used as a reference method in a large number of studies to

$\dagger$ Current affiliation: National Institute for Public Health and the Environment (RIVM), Bilthoven, The Netherlands. validate energy intake both in adults (e.g. references 5-8) and children (e.g. references 1, 9-12). The number of validation studies of FFQ using the DLW method in children is limited ${ }^{(1,13)}$.

The first aim of the present study was to validate the FFQ with respect to energy intake, using the DLW method as a reference method, in 4- to 6-year-old children. In large-scale studies extensive quality control of FFQ is time-consuming and expensive. Therefore an additional aim of the study was to investigate how the extent of quality control influences the validity of the FFQ. In population studies a high response rate is crucial and therefore the burden placed on parents should be limited. In our FFQ we asked parents to measure the content of cups and glasses to have a more precise estimate of beverage portion sizes. To evaluate whether this indeed had a positive effect on the questionnaire's quality, the third purpose of our study was to assess the effect of standard, uniform $v$. individually measured beverage portion sizes on the validity of the FFQ. 


\section{Materials and methods}

\section{Participants}

Parents with children aged 4 to 6 years were recruited from a pool of volunteers from TNO (a Dutch acronym for the Netherlands Organization for Applied Scientific Research) Quality of Life, Zeist, The Netherlands. Recruitment also took place by means of advertisements which were posted at for example primary schools and children's day care. In total twenty-eight parents with thirty apparently healthy children (fifteen boys and fifteen girls) agreed to participate in the study. Written informed consent was obtained from both parents of each participating child after receiving an explanation of the procedures. Before the start of the study all children underwent a medical examination. This examination involved a medical history and measurement of weight and height. An independent medical ethics committee (The Medical Ethics Committee of Tilburg) approved the research protocol. All children completed the study.

\section{Antbropometry}

At the medical examination weight and height of the children were measured. Standing height was measured using a height measure to the nearest $0 \cdot 1 \mathrm{~cm}$ (Leicester Height Measure; Invicta Plastics Limited, Leicester, UK). In addition parents received a weighing scale (type HE-5; CAS corporation, East Rutherford, NJ, USA) and were asked to weigh the child to the nearest $0 \cdot 1 \mathrm{~kg}$ on the weighing scale in the morning of day 2 and day 15 . Children were weighed in their underwear without shoes.

\section{FFQ}

The FFQ was developed based on $2 \mathrm{~d}$ food record data of the third DNFCS ${ }^{(3)}$. The foods in the database were grouped into eighty-five food groups. In order to select food groups relevant for the energy intake of children we used a two-step selection procedure in different age and gender groups of children aged 2-12 years. First, the percentage contribution of each food group to the energy intake was calculated. Food groups were selected until a cumulative contribution of $80 \%$ of the energy intake was achieved. In this way an estimate of the mean energy intake on the population level was established. This first step yielded twenty-two to twenty-six food groups for the different age and gender groups. To capture the variation between subjects in the contribution of food groups to energy intake, food groups were added that contributed more than $2 \cdot 5 \%$ to the energy intake of users of the particular food group and also fulfilled the criterion of being consumed by a minimum of $10 \%$ of users of the food group (step 2). Some food groups with a lower percentage of users were selected as well if the foods might be used by the users on a daily basis (e.g. soya milk). After steps 1 and 2, the thirty-nine to forty-six selected food groups covered $90-93 \%$ of the total energy intake for the different age and gender groups according to the DNFCS. As the selection differed only slightly between the different age and gender groups, it was decided to make one questionnaire for all age groups. The selection of the food groups was the basis for the generation of items. Some food groups were split into different items or combined into one item based on the following criteria: the energy content per portion, the importance of foods within a food group, and whether a food item would be a logical combination of foods for the respondent. This resulted in seventy-one items. For twenty-seven foods additional questions were asked about the specific types or brands consumed and preparation methods. The reference period of the FFQ was the past 4 weeks. Parents indicated their child's habitual consumption frequency of each of the food items by checking one of six frequency categories ranging from 'never' to '6-7 days a week'. Portion sizes were asked for in natural units (e.g. number of apples, slices of bread), household units (e.g. glasses, spoons) or grams (e.g. grams of meat) ${ }^{(14)}$. Parents were asked to measure the volume of glasses and cups used for different types of beverages. Moreover, parents were asked to inquire at their child's day care about the food and beverages that were consumed. From a pilot study it appeared that it took a parent on average 25 (range 10-60) min to complete the questionnaire ${ }^{(2)}$.

On day 15 of the study, parents received the FFQ and were asked to return this by mail within two weeks. After the completed questionnaires were returned, several copies were made in order to study the influence of reviewing and data processing on the validity of the questionnaire. This resulted in different scenarios (see Table 1). The first scenario was a thoroughly reviewed FFQ, where each FFQ was individually reviewed by a dietitian. The dietitian retrieved each missing or rectified each incorrect answer by contacting the parent by telephone. The answers were entered in electronic format and converted to SAS data by means of SAS Vovris, a software package for the processing of $\mathrm{FFQ}^{(15)}$. Output of the data cleaning in SAS Vovris consisted of answers below the minimum or above the maximum amount eaten as defined by the dietitian, missing frequencies, quantities or sort categories and data errors due to data entry, for example non-existing categories. Next the dietitian reviewed all errors and warnings in an iterative process with the cleaning procedures in SAS Vovris. In a next step consistency checks were performed between different items in the questionnaire. The dietitian checked all the output and corrected if necessary. In the second scenario parents were not consulted and the review by the dietitian was less extensive. Recurrent incorrect answers, resulting from the data control in SAS Vovris, were corrected by the dietitian in a uniform way according to a code instruction. One dietitian was responsible for reviewing the FFQ. In order to have no prior knowledge of the answers given in the FFQ, the 


\begin{tabular}{|c|c|c|c|c|}
\hline & $\begin{array}{c}\text { Scenario } \\
1\end{array}$ & $\begin{array}{l}\text { Scenario } \\
\quad 2\end{array}$ & $\begin{array}{l}\text { Scenario } \\
3\end{array}$ & $\begin{array}{l}\text { Scenario } \\
\quad 4\end{array}$ \\
\hline $\begin{array}{l}\text { Extensive review by dietitian for completeness and strange entries and } \\
\text { personal check with parent }\end{array}$ & $\mathrm{x}$ & & & $x$ \\
\hline Less extensive review of FFQ by dietitian according to a code instruction & & $\mathrm{X}$ & & \\
\hline No review by a dietitian & & & $\mathrm{x}$ & \\
\hline Data quality control and data cleaning by data management & $\mathrm{X}$ & $\mathrm{X}$ & $\mathrm{X}$ & $\mathrm{X}$ \\
\hline Individual, measured portion sizes for beverages & $\mathrm{x}$ & $\mathrm{x}$ & $\mathrm{x}$ & \\
\hline Standard, uniform portion size for beverages & & & & $\mathrm{X}$ \\
\hline
\end{tabular}

second scenario review was performed first by the dietitian. This was followed by the thorough review, i.e. the first scenario. The third scenario was that the FFQ was not checked on missing data or consistency by the dietitian. SAS Vovris automatically deleted real errors (double answers and non-existing categories). The fourth scenario was the same as the first scenario, the difference being that the portion sizes as measured by the parents were replaced by standardized beverage portion size of $150 \mathrm{ml}$ per glass. For all scenarios, defaults for missing quantities and missing sort categories (i.e. specific food types, brands and preparation methods) were automatically filled in by SAS Vovris before calculation when they could not or were not traced by the dietitian. For the calculation of energy and nutrient intake the Netherlands Food Composition Table NEVO $2001^{(16)}$ was used. New and/or specific products for children were added by the dietitian.

\section{Doubly labelled water method}

The DLW method was used to estimate the total energy expenditure of the children. DLW was prepared by the University of Maastricht (Department of Human Biology), following standard procedures ${ }^{(17)} \cdot{ }^{2} \mathrm{H}$ was obtained as a solution containing 99.9 atom $\%$ and ${ }^{18} \mathrm{O}$ as an aqueous solution containing 10 atom $\%$. The dose of labelled isotopes was a mixture of 10 atom $\%{ }^{18} \mathrm{O}$ (Campro, Veenendaal, The Netherlands) and 5 atom $\%{ }^{2} \mathrm{H}$ (Cambridge Isotopes, Andover, MA, USA) in proportion to the child's body weight, which was measured during the medical examination. Background urine specimens were collected at home before the subjects came to research centre TNO for consumption of the water solution containing the labelled isotopes $\left({ }^{2} \mathrm{H}_{2}{ }^{18} \mathrm{O}\right)$. Subjects drank the water straight from the bottle and the bottle was rinsed with 50-75 $\mathrm{ml}$ tap water which was consumed as well. The water was consumed as a last consumption before the children went home to go to sleep.

After the consumption of DLW, the ${ }^{2} \mathrm{H}$ is excreted as ${ }^{2} \mathrm{H}_{2} \mathrm{O}$ and ${ }^{18} \mathrm{O}$ is excreted as $\mathrm{H}_{2}{ }^{18} \mathrm{O}$ and $\mathrm{C}^{18} \mathrm{O}_{2}$. In order to measure this excretion, seven urine samples were collected in two weeks. The first sample was the background sample (before consumption of DLW). The other six samples were the second and last voiding of study day 2 , morning and evening voiding of day 9, evening voiding of day 14 and morning voiding of day 15. Urine samples were collected at home and kept in the fridge. Within $24 \mathrm{~h}$ of each collection a research assistant visited the subjects and took the urine samples to research centre TNO. Duplicate samples of each voiding were kept in the freezer $\left(-20^{\circ} \mathrm{C}\right)$ until they were transported to Maastricht University for analysis. Samples were analysed by isotope ratio MS (Optima; VG Isogas, Middlewich, UK). Total daily energy expenditure (EE) was calculated from the rate of $\mathrm{C}^{18} \mathrm{O}_{2}$ production. Detailed information on the procedures followed for urine analysis and subsequent data analysis has been given previously ${ }^{(18)}$.

\section{Statistical analyses}

Statistical analyses were performed using the SAS statistical software package version $8 \cdot 2$ (SAS Institute, Cary, NC, USA). Means and standard deviations were calculated for energy intake (EI) and EE in all children. A paired $t$ test was calculated to determine differences between EI and $\mathrm{EE}$ on a mean level. Additionally, a Bland-Altman plot $^{(19)}$ was used to analyse agreement between EI and EE. This plot of the difference between the two methods against the average of the measurements shows the magnitude of disagreement, spots outliers and identifies trends. Furthermore the EI:EE ratio was calculated to assess the accuracy of the reported energy intake. A value of 1.00 is expected when EI calculated by an FFQ is equal to the measured EE. Pearson correlation coefficients between EI and EE for the total population and partial correlations adjusted for gender were calculated. $P<0.05$ was considered as statistically significant. All children were included in the statistical analyses.

\section{Results}

The characteristics of the children and their parents are shown in Table 2 . The mean age of the children was $5 \cdot 2$ (sD $0 \cdot 7$ ) years and their mean BMI was $16 \cdot 0$ (SD $1 \cdot 4) \mathrm{kg} / \mathrm{m}^{2}$. Children's mean body weight was equal on day 2 and day $15(21.6$ (SD 3.6) kg; within-subject standard deviation $\sigma=0.4751(95 \%$ CI $0 \cdot 3976,0 \cdot 6349))$. Table 2 shows the energy expenditure and energy intake assessed by the extensively reviewed and cleaned FFQ (scenario 1). Mean EI (6117 (SD 1025) kJ/d), as calculated from the extensively reviewed FFQ, did not differ from mean EE (6286 (SD 971) 
Table 2 Characteristics of children and parents, energy intake (EI), energy expenditure (EE) determined with the doubly labelled water method and energy percentage of macronutrients calculated from the FFQ with scenario 1: healthy children aged 4-6 years, The Netherlands

\begin{tabular}{|c|c|c|c|c|c|c|c|c|c|}
\hline & \multicolumn{3}{|c|}{ Total $(n$ 30) } & \multicolumn{3}{|c|}{ Boys ( $n$ 15) } & \multicolumn{3}{|c|}{ Girls $(n$ 15) } \\
\hline & Mean & SD & Range & Mean & SD & Range & Mean & SD & Range \\
\hline \multicolumn{10}{|l|}{ CHILDREN } \\
\hline Age (years) & $5 \cdot 2$ & $0 \cdot 7$ & $4-6$ & $5 \cdot 5$ & 0.6 & $4-6$ & 4.9 & $0 \cdot 7$ & $4-6$ \\
\hline Body weight $(\mathrm{kg})$ & $22 \cdot 1$ & $3 \cdot 6$ & $15 \cdot 7-31 \cdot 0$ & $24 \cdot 2$ & $3 \cdot 3$ & $19 \cdot 3-31 \cdot 0$ & $19 \cdot 9$ & $2 \cdot 5$ & $15 \cdot 7-24 \cdot 7$ \\
\hline Height (m) & $1 \cdot 17$ & 0.08 & $1 \cdot 02-1 \cdot 31$ & $1 \cdot 21$ & 0.07 & $1 \cdot 11-1 \cdot 31$ & $1 \cdot 13$ & 0.06 & $1 \cdot 02-1 \cdot 22$ \\
\hline BMI $\left(\mathrm{kg} / \mathrm{m}^{2}\right)$ & $16 \cdot 0$ & $1 \cdot 4$ & $14 \cdot 3-21 \cdot 9$ & $16 \cdot 5$ & $1 \cdot 7$ & $14 \cdot 8-21 \cdot 9$ & $15 \cdot 5$ & 0.9 & $14 \cdot 3-17 \cdot 2$ \\
\hline$E E(k J / d)$ & 6286 & 971 & $4810-8010$ & 6963 & 821 & $5590-8010$ & 5609 & 546 & $4810-6940$ \\
\hline $\mathrm{El}(\mathrm{kJ} / \mathrm{d})$ & 6117 & 1025 & $3527-7877$ & 6595 & 885 & 4963-7877 & 5640 & 952 & $3527-7062$ \\
\hline Total fat (\% of energy) & 30 & 4 & $22-37$ & 30 & 3 & $25-35$ & 30 & 4 & $22-37$ \\
\hline Total protein (\% of energy) & 16 & 1 & $13-19$ & 15 & 1 & $13-18$ & 16 & 1 & $13-19$ \\
\hline \multirow[t]{2}{*}{ Total carbohydrates ( $\%$ of energy) } & 54 & 4 & $47-65$ & 55 & 4 & $50-63$ & 54 & 5 & $47-65$ \\
\hline & Mean & SD & Range & & & & & & \\
\hline \multirow{3}{*}{$\begin{array}{l}\text { PARENTS }(n \text { 58) } \\
\text { BMI }\left(\mathrm{kg} / \mathrm{m}^{2}\right)\end{array}$} & & & & & & & & & \\
\hline & $25 \cdot 4$ & $3 \cdot 8$ & $19 \cdot 6-35 \cdot 7$ & & & & & & \\
\hline & $n$ & $\%$ & & & & & & & \\
\hline Lower education* & 13 & 22 & & & & & & & \\
\hline Intermediate educationt & 17 & 39 & & & & & & & \\
\hline Higher education $\ddagger$ & 28 & 48 & & & & & & & \\
\hline
\end{tabular}

*Lower level of secondary school.

tHigher level of secondary school and intermediate vocational education.

¥Higher vocational education and university.

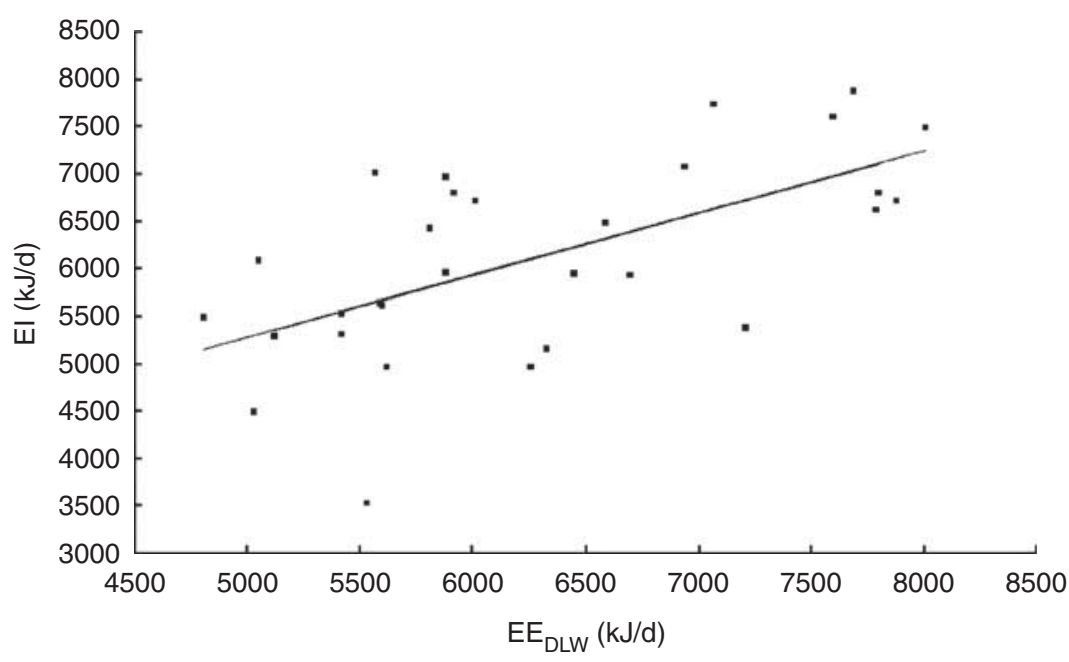

Fig. 1 Energy intake (EI) measured by the extensively reviewed FFQ, in which individually measured beverage portion sizes were taken into account, plotted $v$. total energy expenditure (EE) measured by the doubly labelled water (DLW) method. The straight line is the regression line: $\mathrm{El}(\mathrm{kJ} / \mathrm{d})=2018+0.65 \times \mathrm{EE}(\mathrm{kJ} / \mathrm{d}) ; r=0.62$

kJ; $P=0 \cdot 1496)$. The group average EI deviated from the measured EE by $-3 \%$. Figure 1 shows the scatter plot and results of the regression analysis of EI as calculated from the extensively reviewed FFQ (scenario 1) $v$. EE measured by the DLW method. The Pearson correlation between EI and EE was 0.62 for scenario 1 . The individual differences between EI calculated from the extensively reviewed FFQ and EE were plotted against the mean of EI and EE and the result is depicted in Fig. 2. This Bland-Altman plot shows that the variation between the methods (i.e. difference between EI and EE) was equally distributed with the mean of the two methods $(P=0 \cdot 15)$, indicating that there is no relevant systematic bias. The plot illustrates that both under- and over-reporting of energy intake occurred. The mean EE $v$. EI difference is a measure for the constant bias and is close to zero, namely $169 \mathrm{~kJ}$. The precision window is between -158 and $495 \mathrm{~kJ}$. The width of the $95 \%$ confidence limits of agreement varied from -1580 to $1917 \mathrm{~kJ}$, indicating wide discrepancies between the two methods for some individual subjects. The differences did not tend to increase as the absolute energy values increased. EI and EE were classified into tertiles, showing a 53\% correct classification and a $7 \%$ misclassification. Moreover, misclassification was tested by means of the kappa agreement coefficient which was $0 \cdot 40$, showing a moderate agreement between EI and EE. 


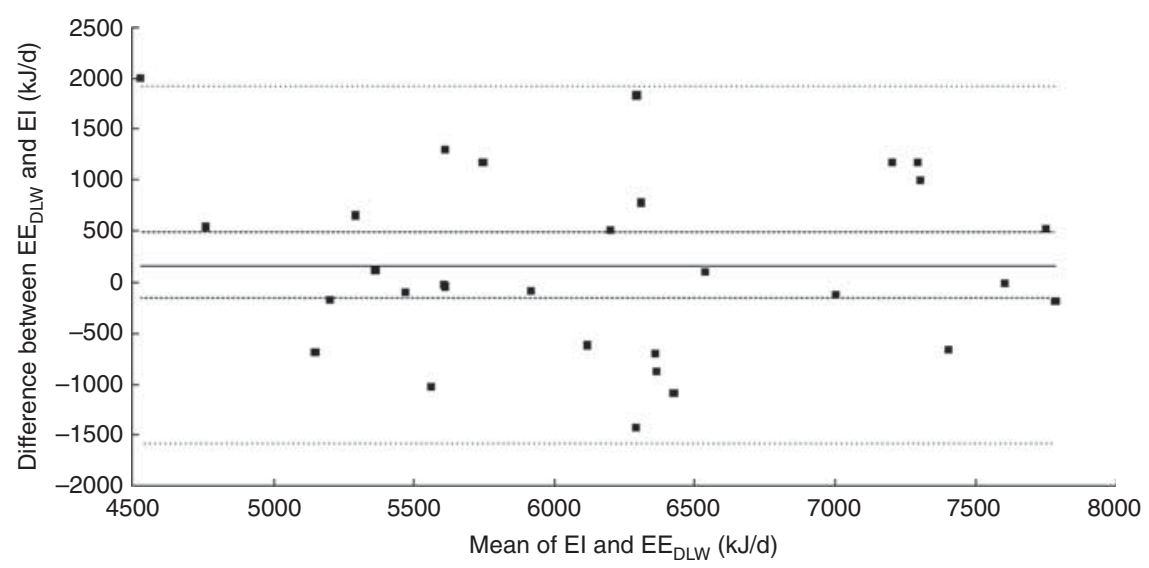

Fig. 2 Individual differences between total energy expenditure (EE) measured with the doubly labelled water method (DLW) and energy intake (EI) calculated by the extensively reviewed FFQ plotted $v$. the mean of the measurements of $E I$ and $E E_{D L W}$. The constant bias is $169 \mathrm{~kJ}(-)$; the precision window is between -158 and $495 \mathrm{~kJ}(---)$; and the width of the $95 \%$ confidence limits of agreement varies from -1580 to $1917 \mathrm{~kJ}(\cdots)$

Table 3 Comparison of energy intake (EI) and ratio of energy intake to energy expenditure (EE) by the doubly labelled water (DLW) method in different FFQ reviewing and data processing scenarios: healthy children aged 4-6 years, The Netherlands

\begin{tabular}{|c|c|c|c|c|c|c|c|c|c|c|c|c|}
\hline & \multicolumn{3}{|c|}{ Scenario 1} & \multicolumn{3}{|c|}{ Scenario $2^{*}$} & \multicolumn{3}{|c|}{ Scenario 3} & \multicolumn{3}{|c|}{ Scenario 4} \\
\hline & Mean & SD & Range & Mean & SD & Range & Mean & SD & Range & Mean & SD & Range \\
\hline \multicolumn{13}{|l|}{ Total ( $n$ 30) } \\
\hline El $(\mathrm{kJ} / \mathrm{d})$ & 6117 & 1025 & $3527-7877$ & 6043 & 1013 & $3527-7887$ & 6081 & 1032 & $3527-7877$ & 5828 & 887 & $3533-7305$ \\
\hline El:EE & 0.98 & $0 \cdot 14$ & $0 \cdot 64-1 \cdot 26$ & 0.97 & $0 \cdot 15$ & $0 \cdot 64-1 \cdot 26$ & 0.98 & $0 \cdot 15$ & $0 \cdot 64-1 \cdot 26$ & 0.94 & $0 \cdot 13$ & $0.64-1.14$ \\
\hline $\begin{array}{r}\text { Pearson } r \\
\text { Boys }(n 15)\end{array}$ & 0.62 & & & 0.56 & & & 0.56 & & & 0.63 & & \\
\hline El $(\mathrm{kJ} / \mathrm{d})$ & 6595 & 885 & $4963-7877$ & 6493 & 914 & $4915-7877$ & 6539 & 939 & $4808-7877$ & 6291 & 733 & $5179-7305$ \\
\hline $\mathrm{El}: \mathrm{EE}_{\mathrm{DLW}}$ & 0.95 & $0 \cdot 13$ & $0 \cdot 75-1 \cdot 19$ & 0.94 & 0.15 & $0 \cdot 74-1 \cdot 24$ & 0.95 & $0 \cdot 15$ & $0 \cdot 74-1 \cdot 24$ & 0.91 & $0 \cdot 11$ & $0 \cdot 72-1 \cdot 10$ \\
\hline \multicolumn{13}{|l|}{ Girls $(n 15)$} \\
\hline El (kJ/d) & 5640 & 952 & $3527-7062$ & 5594 & 928 & $3527-7180$ & 5623 & 934 & $3527-7208$ & 5366 & 796 & $3533-6373$ \\
\hline El:EE & $1 \cdot 01$ & $0 \cdot 16$ & $0 \cdot 64-1 \cdot 26$ & $1 \cdot 00$ & $0 \cdot 16$ & $0 \cdot 64-1 \cdot 26$ & $1 \cdot 01$ & $0 \cdot 16$ & $0 \cdot 64-1 \cdot 26$ & 0.96 & $0 \cdot 14$ & $0 \cdot 64-1 \cdot 14$ \\
\hline
\end{tabular}

*Two questionnaires out of thirty were not filled out properly. According to the standard instruction they should not be considered as valid. For comparison reasons they are included in the analysis.

In Table 3 the mean energy intake between the four scenarios is compared. The mean EI varied from 6117 (SD 1025 ) $\mathrm{kJ} / \mathrm{d}$ in the extensive reviewed FFQ (scenario 1) to 5828 (sD 887) kJ/d when individually measured beverage portion sizes were replaced by standard portion sizes (scenario 4). Pearson correlation coefficients varied between 0.56 and 0.63 . Partial correlations adjusted for gender were somewhat weaker due to the more limited range of EI and varied between 0.41 and 0.46 for the different scenarios.

Mean EI as calculated from the FFQ without review (scenario 3, 6081 (sD 1032) $\mathrm{kJ} / \mathrm{d}$ ) and minimal data cleaning (scenario 2, $6043(\mathrm{sD} 1013) \mathrm{kJ} / \mathrm{d}$ ) did not differ from $\operatorname{EE}(P=0 \cdot 12$ and $P=0 \cdot 08$, respectively). However, for the FFQ with standard beverage portion sizes mean EI $(5828$ (sD 887) kJ/d) differed significantly from mean EE (6286 (sD 971) kJ; $P=0 \cdot 0040)$. When analyses were performed separately for boys and girls, only mean EI of the boys differed significantly from EE (data not shown).

As shown in Table 4, self-measured portion sizes of beverages were on average higher than the standard portion size of $150 \mathrm{ml}$. However, the Pearson correlation coefficient between EI in scenario 4 and EE (0.63) was comparable to the correlation between EI in scenario 1 and EE.

\section{Discussion}

The present study showed that the FFQ developed to assess energy intake in children is a reasonably valid and useful instrument for use in dietary surveys and epidemiological studies in The Netherlands. The mean EI did not differ from EE as measured with the DLW technique. For the total group the mean ratio EI:EE was $0 \cdot 98$, and most $(90 \%)$ subjects were within the limits of acceptable reporters defined as having EI:EE values between 0.76 and $1 \cdot 24^{(20)}$. Pearson's correlation coefficient was $0 \cdot 62$, indicating a reasonable capacity to rank subjects with respect to energy intake in a population of children with a similar narrow age range. The Bland-Altman plot showed that for some individuals the difference between EI and EE was substantial, although the upper and lower limits of agreement were smaller than in other validation studies 
Table 4 Standard and individually measured beverage portion sizes in the FFQ validation study: healthy children aged 4-6 years, The Netherlands

\begin{tabular}{|c|c|c|c|c|c|c|c|}
\hline \multirow[b]{3}{*}{ Beverage } & \multirow[b]{3}{*}{ Standard portion size (ml) } & \multicolumn{6}{|c|}{ Measured portion size (ml) } \\
\hline & & \multicolumn{3}{|c|}{ Boys } & \multicolumn{3}{|c|}{ Girls } \\
\hline & & Mean & SD & $n$ & Mean & SD & $n$ \\
\hline Milk & 150 & 175 & 27 & 11 & 185 & 34 & 14 \\
\hline Buttermilk & 150 & 250 & 0 & 1 & 150 & 35 & 2 \\
\hline Chocolate milk & 150 & 186 & 48 & 7 & 180 & 31 & 10 \\
\hline Milk or yoghurt drink & 150 & 187 & 36 & 11 & 200 & 27 & 6 \\
\hline Soya milk & 150 & - & - & 0 & 188 & 88 & 2 \\
\hline Dessert (custard/yoghurt) & 135 & 156 & 40 & 15 & 151 & 36 & 14 \\
\hline Porridge & 200 & 200 & 0 & 1 & 200 & 50 & 3 \\
\hline Juice & 150 & 171 & 42 & 13 & 178 & 35 & 14 \\
\hline Soft drink & 150 & 186 & 40 & 7 & 193 & 21 & 9 \\
\hline Tea & 150 & 171 & 40 & 6 & 166 & 32 & 9 \\
\hline Water & 150 & 161 & 46 & 14 & 186 & 33 & 15 \\
\hline Lemonade* & 150 & 180 & 44 & 13 & 194 & 36 & 14 \\
\hline
\end{tabular}

*Lemonade $=$ syrup plus added water.

(24h multiple-pass recall and $3 \mathrm{~d}$ record) in children of about the same age ${ }^{(10-12)}$. However, a larger sample size would have resulted in a more precise estimate of the agreement. In Livingstone et al.'s ${ }^{(1)}$ comparison of eleven validation studies in young children the mean EI:EE varied between 0.82 and 1.59 . With respect to the EI:EE ratio, our questionnaire performed much better than the only study that validated an FFQ, in which the mean EI:EE was $1.59^{(9)}$. An important difference is that Kaskoun et $a l .{ }^{(9)}$ used the slightly adopted Willett questionnaire developed for adults, which was not designed to measure energy intake, in contrast to our questionnaire, which is specially developed to measure energy intake in children. Compared with other DLW validation studies of FFQ in adolescents ${ }^{(21)}$ and adults ${ }^{(5,8)}$, our questionnaire performed well to estimate mean EI.

When the DLW method is used as a reference method for energy intake, the assumption must be fulfilled that the subjects are in energy balance, i.e. $\mathrm{EI}=\mathrm{EE}$. Children normally are in positive energy balance; however energy accretion is small, about $1-2 \%$ of $\mathrm{EI}^{(9,22)}$. In our study mean body weight was equal on day 2 and day 15. Furthermore, the period of the EE measurement (15d) was covered by the reference period of 4 weeks of the FFQ.

Under-reporting is always an aspect that needs to be considered. In general people tend to under-report their food intake, but overweight subjects more than those with normal weight (e.g. references 1, 20 and 23). In our study both under- and over-reporting occurred. However, in our study only two boys out of thirty children were overweight. Therefore we do not know if parents tend to under-report food intake of overweight children with our questionnaire. Kaskoun et al. ${ }^{(9)}$ concluded that body composition of children and their parents did not appear to be a strong factor influencing the overestimation of energy intake by FFQ in children. Also O'Connor et al. ${ }^{(11)}$ reported no relationship between misreporting and BMI of the children in their study among 6- to 9-year-olds. In addition, EI and macronutrient composition of the diet in the children participating in our study were comparable to those found in a recent Dutch population study among 4- to 6-year-olds ${ }^{(24)}$.

Bellisle ${ }^{(23)}$ included in his overview several DLW studies in children and concluded that intake data of young children are more valid than intake data of adults. One possible explanation for the more accurate reporting in children is that an observer (parent, caregiver) does the reporting $^{(4,23)}$. Also Hise et al. ${ }^{(6)}$ found that the combination of observer-recorded food records with snack recalls is a valid method for measuring EI in overweight and obese subjects. Livingstone et $a l^{(1)}$ concluded that parents can be reliable reporters of their children's food intake in the home environment, but probably not of their children's out-of-home food intake. In the present study, parents were responsible for filling out the FFQ and also parents were in control of most of the food intake of their child. However, as our questionnaire is intended for use in children between 2 and 12 years of age, the validity of the FFQ might decrease with increasing age because parents are less in control of older children's food intake.

In large population and epidemiological studies it is not always possible to contact parents when values filled out are not clear or questions are skipped, and to review each questionnaire extensively. Therefore, we evaluated how a review by a dietitian in a standardized manner, without contacting the parents, influences the validity. It appeared that with this less extensive standardized review the validity of the FFQ decreased only slightly. Therefore, in large population or epidemiological studies a less extensive review by a dietitian seems justified. In two out of thirty subjects it was, according to the standard instruction, indicated that we should consider the questionnaire as unreliable as two pages were skipped. Therefore, depending on the standard instruction, it might be that 
more subjects would be excluded as a result of missing values in the less extensive reviewing situation. Excluding subjects when subject characteristics are correlated with reasons for excluding might influence survey value. In our small sample size we were not able to investigate whether subject characteristics were related with lower questionnaire quality. We also investigated the research situation with minimal resources in which a review by a dietitian is not possible at all. In this scenario 3 the mean energy intake decreased as in scenario 2, but the FFQ still remained reasonably valid. As the parents and children in our study participated in a small intensive study, it is possible that the parents completed the questionnaire very accurately and truthfully. If this indeed happened, necessary corrections were limited and this might partly explain why we found only small differences between the different reviewing scenarios.

In our questionnaire parents were asked to measure the content of glasses and cups of several beverages. Measuring beverage portion sizes gives participating parents an extra burden and might have a negative effect on response rates in larger studies. Therefore we also investigated the effect of using a standard beverage portion size instead of self-measured portion sizes. When the standard beverage portion size was used, the resulting lower EI differed significantly from EE and EI:EE decreased to 0.94. Although this could be partly explained by the prevention of overreporting (EI:EE $>1 \cdot 24)^{(20)}$, it appeared that the standard portion size applied for beverages $(150 \mathrm{ml})$ was too small. Replacing the self-measured beverage portion sizes with the standard size did not reduce the ranking capacity of the FFQ, possibly because self-measurement of volumes not only adds information, but also measurement error. This does not apply to portion sizes of other foods, which were asked for in natural units (e.g. number of apples, slices of bread), household units (e.g. spoons) or grams (e.g. grams of meat). As in general these portion sizes are not standard portion sizes used for adults, we do not expect that overestimating of serving sizes occurred in our questionnaire, suggested as the most likely source of bias in the study of Kaskoun et $a l^{(9)}$. Further, the present study indicates that the chosen standard portion size for beverages for children needs to be revised. However, it should be kept in mind that the number of subjects in the current study was limited.

In summary, data from the present study showed that the developed FFQ is a valid instrument to estimate mean energy intake in a group of 4- to 6-year-old children and performs reasonably well to rank the subjects with respect to energy intake. It is therefore a useful instrument to estimate energy intake in children in surveys and epidemiological studies in The Netherlands. Intensive quality control may enhance the validity of the FFQ only marginally. Using a standard beverage portion size (of $150 \mathrm{ml}$ ) increases under-reporting. This could be resolved by replacing the standard beverage portion size in this age group with a higher size. To determine the size of a new standard beverage portion, a study in a larger population of children is necessary.

\section{Acknowledgements}

Source of funding: This work was supported by the Dutch Ministry of Health, Welfare and Sports. Conflict of interest: None declared. Author contributions: A.E.D. was responsible for writing the manuscript. A.S., A.K. and W.J.A.M. were involved in design of the study. H.A.M.B. was involved as dietitian in the study. K.R.W. was responsible for the DLW method. C.K. analysed the data. R.A.G. and A.S. were involved in writing the manuscript. Acknowledgments: We thank all parents, children and employees of the metabolic unit of TNO Quality of Life involved in the conduct of the study for their efforts.

\section{References}

1. Livingstone MBE, Robson PJ \& Wallace JMW (2004) Issues in dietary intake assessment of children and adolescents. Br J Nutr 92, Suppl. 2, S213-S222.

2. Brants H, Stafleu A, Ter Doest D et al. (2006) Ontwikkeling van een voedselfrequentievragenlijst: energie-inname van kinderen van 2 tot en met 12 jaar (Development of a food frequency questionnaire: energy intake of children 2-12 years of age). Voeding $N U \mathbf{2}, 25-28$.

3. Anon. (1998) Zo eet Nederland, 1998. Food Consumption Survey 1997-1998. Den Haag: Voedingscentrum.

4. Hill RJ \& Davies PSW (2001) The validity of self-reported energy intake as determined using the doubly labeled water technique. Br J Nutr 85, 415-430.

5. Anderson LF, Tomten H, Haggarty P et al. (2003) Validation of energy intake estimated from a food frequency questionnaire: a doubly labeled water study. Eur J Clin Nutr 57, 279-284.

6. Hise ME, Sullivan DK, Jacobsen DJ et al. (2002) Validation of energy intake measurements determined from observerrecorded food records and recall methods compared with the doubly labeled water method in overweight and obese subjects. Am J Clin Nutr 75, 263-267.

7. Koebnick C, Wagner K, Thielecke F et al. (2005) An easyto-use semiquantitative food record validated for energy intake by using doubly labeled water technique. Eur J Clin Nutr 59, 989-995.

8. Kroke A, Klipstein-Grobusch K, Voss S et al. (1999) Validation of a self-administered food frequency questionnaire administered in the European Prospective Investigation into Cancer and Nutrition (EPIC) Study: comparison of energy, protein, and macronutrient intakes estimated with the doubly labeled water, urinary nitrogen, and repeated 24-h dietary recall methods. Am J Clin Nutr 70, 439-447.

9. Kaskoun MC, Johnson RK \& Goran MI (1994) Comparison of energy intake by semiquantitative food-frequency questionnaire with total energy expenditure by the doubly labeled water method in young children. Am J Clin Nutr 60, 43-47.

10. Montgomery C, Reilly JJ, Jackson DM et al. (2005) Validation of energy intake by 24-hour multiple pass recall: comparison with total energy expenditure in children. Br J Nutr 93, 671-676.

11. O'Connor J, Ball EJ, Steinbeck KS et al. (2001) Comparison of total energy expenditure and energy intake in children ages 6-9 y. Am J Clin Nutr 74, 643-649. 
12. Reilly JJ, Montgomery C, Jackson D et al. (2001) Energy intake by multiple pass $24 \mathrm{~h}$ recall and total energy expenditure: a comparison in a representative sample of 3-4-year-olds. Br J Nutr 86, 601-605.

13. McPherson RS, Hoelscher DM, Alexander M et al. (2000) Dietary assessment methods among school-aged children: validity and reliability. Prev Med 31, Suppl. 2, S11-S33.

14. Anon (1997) Maten, gewichten, code nummers (Measures, Weights, Code Numbers). Wageningen: Wageningen University.

15. Bouman M, Brants HAM \& Kistemaker C (2000) Vragenlijsten Verwerkingssysteem met SAS (SAS/Vovris). Deel 1 Gebruikershandleiding (Questionnaire Processing System with SAS (SAS/Vovris). Part 1 - User Manual). Zeist: TNO Food and Nutrition.

16. Anon (2002) NEVO tabel 2001. Nederlands voedingsstoffenbestand 2001 (NEVO Table 2001. Netherlands Food Consumption Table). Den Haag: Stichting Nederlands Voedingstoffenbestand, Voedingscentrum.

17. Westerterp KR, Wouters L \& van Marken Lichtenbelt WD (1995) The Maastricht protocol for the measurement of body composition and energy expenditure with labeled water. Obes Res 3, Suppl. 1, 49-57.
18. Westerterp KR (1999) Body composition, water turnover and energy turnover assessment with labelled water. Proc Nutr Soc 58, 945-951.

19. Bland JM \& Altman DG (1986) Statistical methods for assessing agreement between two methods of clinical measurement. Lancet 1, 307-310.

20. Livingstone MBE \& Black AE (2003) Markers of the validity of reported energy intake. J Nutr 133, Suppl. 3, 895S-920S.

21. Perks SM, Roemmich JN, Sandow-Pajewski M et al. (2000) Alterations in growth and body composition during puberty. IV. Energy intake estimated by the youth-adolescent foodfrequency questionnaire: validation by the doubly labeled water method. Am J Clin Nutr 72, 1455-1460.

22. Livingstone MBE \& Robson PJ (2000) Measurement of dietary intake in children. Proc Nutr Soc 59, 279-293.

23. Bellisle F (2001) The doubly-labeled water method and food intake surveys: a confrontation. Rev Nutr Campinas 14, 125-133.

24. Ocké MC, Rossum CTM van, Fransen HP et al. (2008) Dutch National Food Consumption Survey - Young Children 2005/2006. RIVM Report no. 35007001/2008. Bilthoven: RIVM. 